\title{
Development of the saw cylinder for gins and linters with use of new elements of the design
}

\author{
Azamat Sultonov ${ }^{1}$, Mirsolikh Agzamov ${ }^{2}$, Mashkhur Rakhmatov ${ }^{1,2}$, Mirkhosil Agzamov ${ }^{2 *}$, \\ and Khasan Nosirov ${ }^{2}$ \\ 1،"Bukhara agroklaster" LLC, 200103 Bukhara, Uzbekistan \\ ${ }^{2}$ Tashkent Institute of Textile and Light Industry, 100100 Tashkent, Uzbekistan
}

\begin{abstract}
Article issues of decrease in amplitude of dynamic fluctuations of saw cylinders of gins and linter for the purpose of reduction of a deviation of saws from the plane of rotation and contact with saws of grates are consecrated. Mathematical models for calculation of flexural fluctuations of a shaft of a saw cylinder, taking into account intensity of placement of the mass moments of inertia, a technique of the solution of the equation of flexural fluctuations of a saw cylinder with variable intensity of weight and flexural rigidity of sections are given. Data on a new design of saw cylinders with use between the saw laying made on a polymeric basis and equipped with steel pins.
\end{abstract}

\section{Introduction}

One of the main knots having considerable impact on stability of technological process of a ginning is the saw cylinder. In the course of a ginning the saw cylinder is influenced by considerable loadings [1]. It is known that the insufficient durability and rigidity of a saw cylinder, leads to increase in amplitude of its fluctuations and it will negatively affect in the course of a ginning and to damage of seeds and fibers. Therefore details of a saw cylinder at design subject to power calculations [2].

The following production requirements are imposed to a saw cylinder of gin [3]:

- it has to have high fascinating ability for ensuring the set performance and uninterrupted rotation of the adobe roller;

- saw disks have to be rigidly fixed on a shaft, not change the situation in operating time and at rotation of a cylinder to pass strictly on the center of a slot-hole gap between grates;

- the deflection of a shaft is allowed no more than 0.3-0.4 $\mathrm{mm}$ and face beating of saws at rotation not higher than $0.15 \mathrm{~mm}$, otherwise changes the provision of a saw in a slot-hole gap.

At a big deflection or amplitude of fluctuations of a saw cylinder there can be a contact with saws of grates, and it as was shown by results of researches, leads to intensive wear of grates $[4,5]$. Apparently from the aforesaid for stable course of process of a ginning and receiving quality products an important role is played by rigidity of a saw cylinder [6].

\footnotetext{
* Corresponding author: agzamov85@mail.ru
} 
Determination of static rigidity of a shaft of a saw cylinder, vibration of a saw cylinder and determination of its critical speeds, elasticity of support, the gyroscopic moment of disks [7].

\section{Materials and Methods}

This chapter the change of flexural fluctuations of a shaft depending on rigidity of a saw cylinder is considered.

For the solution of an objective it is required preliminary researches of the modes of functioning of a saw cylinder under action on it external loadings. For this reason this problem can be solved as complication of a row by method of the analysis of flexural fluctuations of saw cylinders of gins [8]. The complexity of a solvable task is that the saw cylinder of gin is characterized by rather long distance between support, variable intensity of weight and flexural rigidity on length caused by the fact that the saws and between saw laying having various rigidity because of a difference of characteristics of the used material and also accumulation of an imbalance from uneven placement of saws concerning shafts and wear of surfaces of the last participate in execution of external loadings [9].

On the basis of the aforesaid works on drawing up the following mathematical models are performed [10]:

- flexural fluctuations of a shaft of a saw cylinder of the gin brought to a system with constant intensity of weight and flexural rigidity;

- flexural fluctuations of a shaft of a saw cylinder of gin, taking into account intensity of placement of the mass moments of inertia of saws;

- flexural fluctuations of a shaft of a saw cylinder of gin, with variable intensity of weight and flexural rigidity of sections.

By drawing up mathematical models materials of the known researches $[3,4]$ the following assumptions are made.

The shaft of a saw cylinder of gin has constant average intensity of weight on all length.

$$
m_{s h}=\frac{G_{n}+G_{s h}}{g+L}
$$

where: $G_{n}$ - total mass of a package of saws of between saw laying; $G_{s h}=\frac{\pi * \gamma}{4 * g} * d_{s h}^{2} * L$ mass of a shaft of constant diameter on all its length; $Z=0 \div L, L$ - distance between hinges of two support of a shaft; and, $g$ - acceleration of gravity.

Consider that the flexural rigidity of a shaft of gin is defined by the geometrical sizes of diameter of $d_{s h}$ and equal

$$
R_{s h}=\frac{\pi}{64} * d_{s h}^{4} * E
$$

where $E$ - the module of elasticity of the first sort for shaft material.

Consider that rotation of a shaft is characterized by function of angular speed $\omega$ angular acceleration $\varepsilon$, influence of technological and dynamic loads in two $Z X$ and $Z Y$ planes at placement of axis $Z$ on a geometrical axis of rotation of a shaft of $O_{1} O_{2}\left(O_{1}\right.$ and $O_{2}$ characterize placement of hinges of support of a shaft at $\mathrm{O}_{1} \mathrm{O}_{2}=L$ ). We consider existence of the console site of a shaft in the subsequent through regional conditions of the solution of a problem of flexural fluctuations. We enter two mutually perpendicular coordinates of elastic flexural deformations of $Y(t, Z)$ and $X(t, Z)$, functions of time of $t$ and coordinate of placement of sections $Z$ concerning a support in thus $O_{l}$. 
The intensity of external technological and dynamic loading of the shaft is characterized by the functions $n_{y}(t, Z), n_{x}(t, Z)$ applied in the planes $Z Y$ and $Z X$.

Taking into account the entered assumptions for a shaft of gin the following system of the equations of flexural fluctuations was received:

$$
\begin{gathered}
\frac{\partial^{2} Y}{\partial t^{2}}+K^{4} * \frac{\partial^{4} Y}{\partial Z^{2}}-Y * \omega^{2}+2 * \frac{\partial X}{\partial t} \omega+X * \varepsilon=\frac{n_{Y}(t, X)}{m_{B}} \\
-2 * \frac{\partial Y}{\partial t} * \omega-Y * \varepsilon \frac{\partial^{2} X}{\partial t_{2}}+K^{4} \frac{\partial^{4} X}{\partial Z^{4}}-X * \omega^{2}=\frac{n_{X}(t, X)}{m_{B}}
\end{gathered}
$$

where, $K^{4}-R_{s h}: m_{s h}$.

For use of these equations in practical calculations it is necessary to determine frequencies of own fluctuations of a shaft of gin under $\mathrm{n}$ conditions $n_{Y}(t, X)=n_{X}(t, X)=0$.

As a first approximation solutions of the equations (3), (4) we find in the form of ranks, by Fourier's method.

$$
Y(t, Z)=\sum_{i=1}^{\infty} B_{i}(t) * \sin \left(\frac{i^{*} \pi * Z}{L}\right), \quad X(t, Z)=\sum_{i=1}^{\infty} A_{i}(t) * \sin \left(\frac{i * \pi * Z}{L}\right)
$$

where $i=1,2,3, \ldots$ - serial number of a form of fluctuations; and, $A_{i}(t)$ and $B_{i}(t)$ - function of deflections of a shaft, in planes $X Z$ and $Y Z$.

After substitution of private derivatives from (5) in (3) and (4) will receive the system of the equations

$$
\begin{gathered}
\ddot{A}_{i}+\left(Q^{2}-\omega^{2}\right) * A_{i}-2 * \omega^{*} \dot{B}_{i}-\varepsilon^{*} B_{i}=0 \\
\ddot{B}_{i}+\left(Q^{2}-\omega^{2}\right) * B_{i}-2 * \omega^{*} \dot{A}_{i}-\varepsilon^{*} B_{i}=0
\end{gathered}
$$

where, $Q=\frac{i^{2} * \pi^{2}}{L^{2}} * \sqrt{R_{s h} / m_{s h}}$.

$" i "$ - the frequency of own fluctuations of the shaft rotating on absolutely rigid support

$$
\ddot{A}=\frac{\partial^{2} A_{i}}{\partial t^{2}}, \dot{A}=\frac{\partial A_{i}}{\partial t}, \ddot{B}=\frac{\partial^{2} B_{i}}{\partial t^{2}}, \dot{B}=\frac{\partial B_{i}}{\partial t} .
$$

The shaft of a saw cylinder of gin is characterized by the movement the established angular speed $\omega \approx$ const, when $\varepsilon \approx 0$; in this case (6) comes down to the system of the linear equations which are characterized by the decision:

$$
\begin{gathered}
A_{i}(t)=C_{1} * \cos \left(\alpha_{1} * t\right)+C_{2} * \sin \left(\alpha^{*} t\right)+C_{3} * \cos \left(\beta^{*} t\right)+C_{4} * \sin \left(\beta^{*} t\right) \\
B_{i}(t)=-C_{1} * \sin \left(\alpha_{1} * t\right)+C_{2} * \cos \left(\alpha^{*} t\right)+C_{3} * \sin \left(\beta^{*} t\right)+C_{4} * \cos \left(\beta^{*} t\right)
\end{gathered}
$$

where, $\alpha=Q-\omega$ and $\beta=\omega-Q$, and $C_{1}, C_{2}, C_{3}, C_{4}$ - any constants defined from entry conditions. 
Conditions of resonant fluctuations of a shaft of saw gin correspond to $Q=\omega$. Therefore we lead up the approximate analysis of possibility of such fluctuations.

The analysis is made for two types of saw cylinders of gins 3XDD and DP-130 since they differ on length and on diameter of a shaft:

- for shafts of saw gins 3XDD $L=1.7 \mathrm{~m}$; length of a package of saws of $L_{s}=1.5 \mathrm{~m}$; thickness of saws $\delta_{s}=0.95 \mathrm{~mm}$, thickness of between saw laying $Z_{0}=17.05 \mathrm{~mm}$, diameter of shaft $d_{s h}=61.8 \mathrm{~mm}$, diameter of a package drank $D_{s}=310 \mathrm{~mm}$;

- for shafts of saw gins of DP-130 type length of a package of saws of $L_{s}=2.4 \mathrm{~m}$ are accepted; thickness of saws $\delta_{s}=0.95 \mathrm{~mm}$, thickness of between saw laying of $Z_{0}=17.05$ $\mathrm{mm}$, diameter of a shaft $d_{s h}=100 \mathrm{~mm}$, diameter of a package drank $D_{s}=310 \mathrm{~mm}$.

Let's give an example of calculation of the first frequency of own fluctuations of a shaft of gin. Count the mass of a shaft $G_{s h}$ diameter of $d_{s h}=61.8 \mathrm{~mm}$ and a package of saws with a diameter of $D=310 \mathrm{~mm}$ at $\gamma=7.8 \mathrm{~g} / \mathrm{cm}^{3}$ :

$$
\begin{gathered}
G_{s h}=\pi / 4 * 7.8 * 61.8^{2} * 10^{-3} * 170=39.8 \mathrm{~kg} \\
G_{s}=\pi / 4 * 31^{2} * 1500 / 17,05 * 7.8 * 10^{-3} * 0.095=90.4 \mathrm{~kg}
\end{gathered}
$$

Defining the given value of intensity of weight:

$$
m_{s h}=\frac{G_{s h}+G_{s}}{981+170}=0.781 * 10^{-3} \mathrm{kgs}^{2} / \mathrm{cm}
$$

Determining flexural rigidity of a shaft at $E=2.1 * 10^{6} \mathrm{kgs}^{2} / \mathrm{cm}$ :

$$
R_{\text {sh }}=\mathrm{E} * \pi / 64 * 61.8^{4}=1.54 * 10^{8} \mathrm{~kg} * \mathrm{~cm}^{2}
$$

Counting the first frequency of own fluctuations of a shaft:

$$
Q_{1}=\frac{\pi^{2}}{L^{2}} * \sqrt{\frac{R_{s h}}{m_{s h}}}=\frac{\pi^{2}}{170^{2}} * \sqrt{\frac{15.4}{0.781 * 10^{10}}}=1531 / \mathrm{s}
$$

For shafts of the second type we will receive:

$$
\begin{gathered}
G_{s h}=\pi / 4 * 10^{2} * 7.8 * 260 * 10^{-3}=159 \mathrm{~kg} \\
n=90.4 * 2.4 / 1.5=144.6 \mathrm{~kg} \\
m_{s h}=\frac{159.2+144.6}{981 * 260}=1.19 \mathrm{kgs}^{2} / \mathrm{sm} \\
R_{s h}=2.1 * 106 * \pi / 64 * 104=1.03 * 109 \mathrm{~kg} * \mathrm{sm}^{2} \\
Q_{1}=\frac{\pi^{2}}{260^{2}} * \sqrt{\frac{1.03}{1,19 * 10^{10}}}=136.71 / \mathrm{s}
\end{gathered}
$$

The executed examples of calculation showed that for shafts of saw gins of size $Q_{1}$ are close to 1 the circular frequency of their rotation (at $p_{s h}=750 \mathrm{rpm}$ ) $-\omega=\pi / 30 * 750 \approx$ $78.5(1 / s)$.

With partial participation of a package of saws at increase in $R_{s h}$ the emergence of resonant fluctuations of these shafts is possible. Therefore carrying out the specified analysis of flexural fluctuations of shafts is expedient.

The possibility of such simplification follows from the equations (3), (4) under conditions, when $\varepsilon \approx 0$ and $\omega \approx$ const. However in this case we enter functions of 
variable intensity of mass of $m(t, Z)$ flexural rigidity $R(1, Z)$ characteristic of saw cylinders of gins. Let's analyze the real reasons of emergence of these functions. At impact of the technological or dynamic loading caused by imbalance of mass of $G_{s}$ of saws of rather geometrical axis $O_{1} O_{2}$, the shaft is bent with placement of its neutral axis on some curve $\mathrm{O}_{1} \mathrm{O}_{M} \mathrm{O}_{2}$, at the same time in a point of $M$ the maximum deflection of $Y_{m}$ (1) through time intervals is reached $m_{s h}=2 * \pi / \omega_{s h}$ a bend on radius $r_{s h}$. Sections of three saws at not deformed condition of a shaft $\left(Y_{m}=0\right)$ are characterized by provisions $D B, A G$ and $C E$. At achievement of $Y_{m}\left(\tau_{s h}\right)$ the same saws are placed on the $D_{l} B_{l}, G_{l} A_{l}, E_{l} C_{l}$ with change of distances $2 * a_{1}=B_{1} C_{1}<Z_{0}$ and $2 * a_{2}-D_{l} E_{l}>Z_{0}$. In a zone of compression of saws and between saw laying on a radius arch $r_{c}=r_{s h}-P_{c}$ is observed the maximum kinematic compression of sections of rings to size $Z_{c}=Z_{0} *\left(1-P_{c} / r_{s h}\right)$. Within a corner $\varphi=0 \div$ $\pi$ turn of a saw cylinder in the compressed zone each point $1 \varphi$ compression of a ring of between saw laying it is characterized by variables to $P_{c}(\varphi)$ and $Z_{c}(\varphi)$. Each characteristic point on the surface of between saw laying, saws and a shaft during time $t=0 \div 0.5 * T_{\text {sh }}$ it appears in a compression zone (fig. 1, a), and the subsequent time of $t=0.5 * T_{\text {sh }} \div$ $T_{s h}$ these points are unloaded. Presence of elastic forces in material of between saw laying allows their deformations to $Z_{k d}>Z_{k}$ (under the terms of two kinematics of process of Fig. 1 , a). Therefore according to fig. 1, saws would have to be deformed (to be bent) moving of sections to the shaft bend planes on $f_{n i}-Z_{k d} \bullet \bullet f_{n 9}=5 *\left(Z_{k d}-Z_{k k}\right)$. Taking into account fig. 1, that $Z_{k d}(t)$ - is cd function of time of $t$ and corner $\varphi$. The analysis of conditions of deformation - compression of rings is characterized by tension:

$$
\sigma_{k d}(t)=E_{A} * \varepsilon_{k d}=E_{A} * Z_{k d}(t) / Z_{k}
$$

where, $E_{A}$ the module of elasticity of the first sort for material of between saw laying.

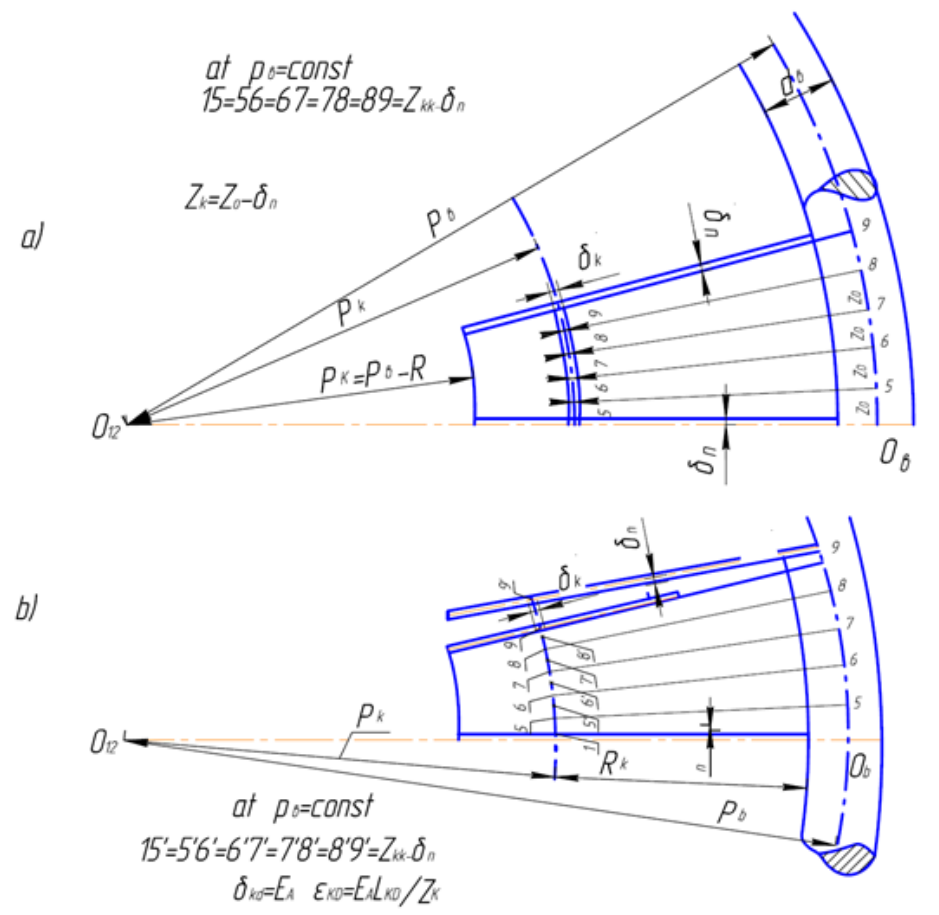

Fig. 1. Scheme for calculation of deformation of rings of between saw laying under the influence of a shaft bend at an angle of rotation $\varphi=0.5 \pi$ 
For a single saw (Fig. 2) its deformation is characterized by use of variable flexural rigidity $I_{n}(R)=\delta_{n}^{3} / 6 * R * \cos \left(\pi * R / R_{n}\right)$ depending on distance $R$ to point of contact of saw ring to which the intensity of external loading of $q_{n}(R)$ is transferred. The carried-out analysis of conditions of loading of between saw laying and saws confirms the difficult phenomena of processes of functioning of saw cylinders of gins at which "the package drank a part of flexural rigidity of a system - between saw laying" promotes change of flexural rigidity of a saw cylinder. Therefore it is expedient to consider problems of flexural fluctuations of model of a saw cylinder of gin direct accounting of existence of the "package drank-between saw laying" system which is strictly connected with shaft.

We consider function of variable intensity on length of a saw cylinder in a look:

$$
m(Z)=M_{s h} * e^{i_{M} * \sin (\pi * Z / L)}
$$

where, degree of " $i$ " is defined from a condition:

$$
i_{M}=L_{s}\left(m_{s} / m_{s h}\right)
$$

at $\left.m_{s}=m_{s h}+G_{s} / L_{s}\right)$ and $m_{s h}=G_{s h} / L_{s h} ; G_{s h}$ and $G_{s}$ - the mass of the site of a shaft length $L$ according to fig. 2 and the block of saws and between saw laying on the site of a shaft $\mathrm{O}_{3} \mathrm{O}_{4}$.

The scheme for calculation of deformation of rings of between saw laying and a bend of saws under the influence of a shaft bend at an angle of rotation (Fig. 2).

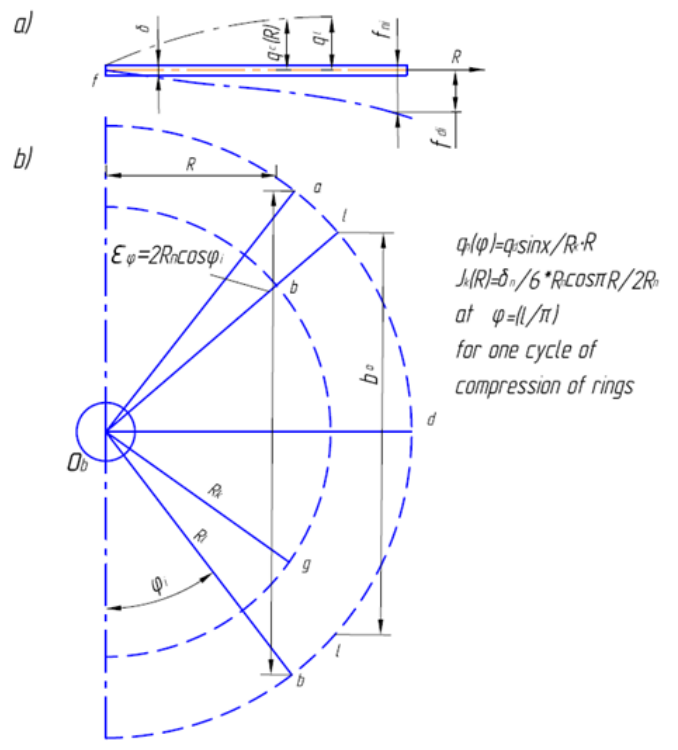

Fig. 2. The scheme for calculation of flexural fluctuations of a saw for one cycle of compression $(\varphi=0 \div \pi)$

The flexural rigidity of sections of a saw cylinder between supports is represented by function

$$
R(Z)=R_{S h} * e^{i * \sin (\pi * Z / L)}
$$


at $R_{s h}=\pi / 64 * d_{s h}^{4} * E$

$$
i=1_{s}\left(R_{m} / R_{s h} * \lambda_{R}\right)
$$

where, $\quad R_{m}=n / 64 * d_{s h}^{4} * E ; \lambda_{R}$ - share coefficient of participation of section of a package of saws and between saw laying in change of flexural rigidity of a saw cylinder on the site of $\mathrm{O}_{3} \mathrm{O}_{4}$; and, $\mathrm{E}$ - module of elasticity of material of between saw laying.

We consider the average intensity of technological loading of a saw cylinder caused the center of gravity (C.G.) with an eccentricity of $E_{S}$ placements of a package of saws and between saw laying of rather geometrical axis of rotation $O_{1} O_{2}$ and influence of centrifugal forces $Q_{s}(t)=\frac{G_{s}}{g} * E_{s} * \omega_{s h}^{2} * \cos \left(\omega_{s h} * t\right)$. Replace these efforts in the $Z Y$ plane with equivalent intensity (distributed) forces

$$
q_{y}(t)=Q_{s}(t) / L=q_{a} * \cos \left(\omega_{s h} * t\right)
$$

\section{Practical work on the development of a new gasket}

The executed decisions show that in cases of absolute and rigid communication of saws with shaft the significant increase in frequency of own fluctuations of a saw cylinder [8] is reached, and at the same time work of the last on the resonant modes of fluctuations is excluded. However constructive realization of such communications demands qualitatively new manufacturing techniques and repair of saw cylinders [9]. On the basis of the received mathematical models [10] amplitudes of fluctuations for saw cylinders at various coefficients of rigidity of material of between saw laying are calculated and the graphic dependence (Fig. 3) (durability of cast aluminum on compression of $42 \mathrm{~kg} / \mathrm{mm}^{2}$, of steel 98 $\mathrm{kg} / \mathrm{mm}^{2}$ )

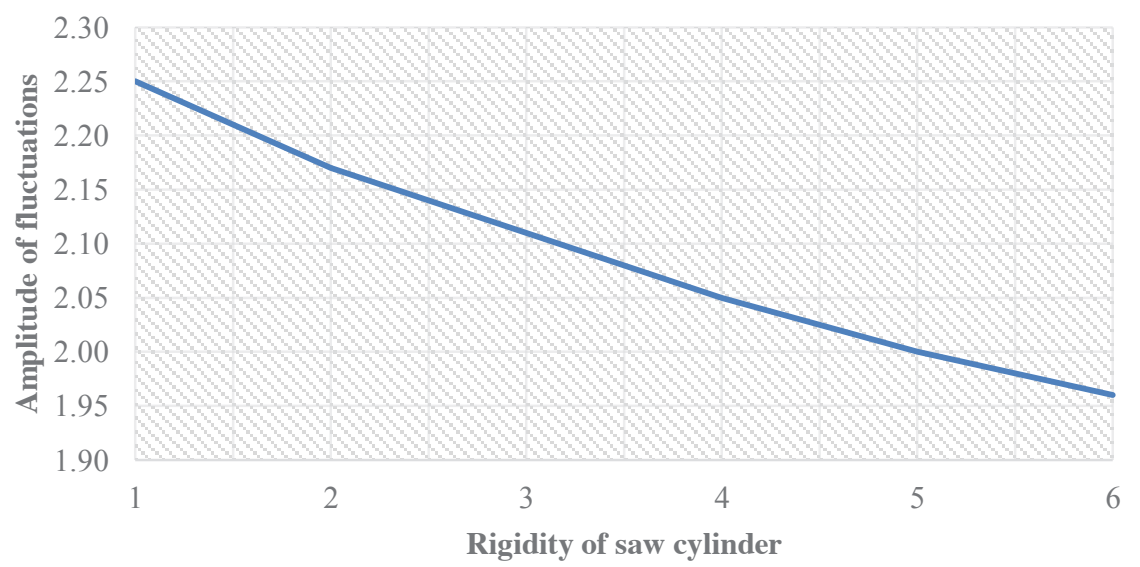

Fig. 3. Change of amplitude of fluctuations depending on rigidity saw cylinder

In all known saw cylinders of gins, the between saw laying made of aluminum is used now. Lack of this saw cylinder is use of scarce non-ferrous metal - aluminum, deformation of aluminum laying, excessive weight and high cost.

For an exception of use of scarce non-ferrous metal, weight reduction and cost of a saw 
cylinder, an expense of the electric power of the saw cylinder spent for rotation and increases in service life of a saw cylinder, it was offered to use the laying made of polymeric material. Laying is supplied with the metal pins which are built in their basis located at identical distance from the center of a shaft and from each other and the fillet located on an internal, face surface of a basis. Between saw laying (Fig. 4 and 5) consists of the basis 1 made of polymeric material, and having concentrically located metal pins 2 which are built in a basis at identical distance from the center and from each other on an internal face surface of a basis there is a fillet 3 . The fillet 3 executed with possibility of free entry into a spline groove of a shaft of a saw drum.

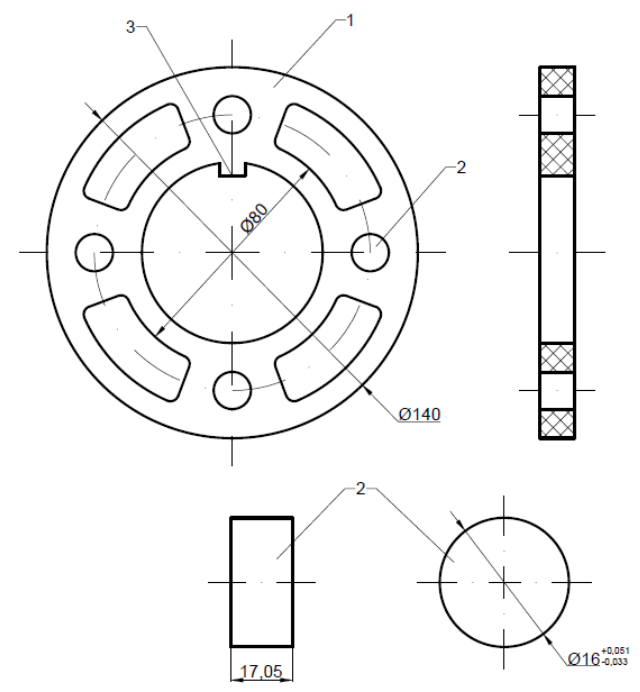

Fig. 4. Polymeric between saw laying bases

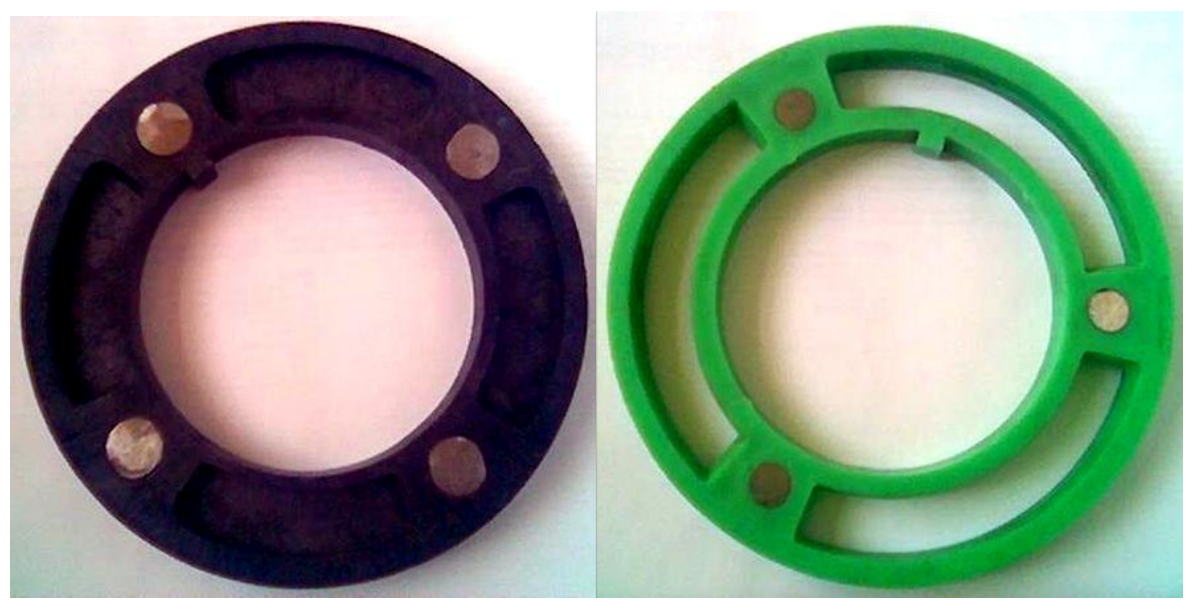

Fig. 5. Polymeric between saw laying

Performance of a basis of between saw laying allows to exclude use of scarce nonferrous metal from polymeric material - aluminum, to lose the weight of the saw drum and as a result an expense of the electric power spent for its rotation since the offered between saw laying has lower weight, than metal [10].

Equipment of between saw laying by steel pins provides the accuracy of between saw 
distances and increase in service life of a saw cylinder.

It is known that the inhaling of circular saws and between saw laying on a shaft is carried out by effort up to 5 tons. In process of operation of saw reels, their saws become dull and through certain time the reel has to be disassembled for change of saws with new. At frequent change of saws and banners the aluminum laying is deformed and loses the sizes and as a result distances between saws of a saw cylinder are not maintained that is inadmissible. When using metal, for example, steel pins it is provided more exact sizes of between saw distances and service life of between saw laying since steel has higher durability on compression in comparison with aluminum or its alloys increases and at reinhalings it is not deformed and does not lose the sizes $[9,10]$. At production of pins from more high-strength metals or alloys they will work even more effectively.

The arrangement of metal pins at identical distance from the center of a shaft and from each other is necessary for ensuring the required residual imbalance of a saw drum.

The fillet located on an internal face surface of a basis at assembly enters a spline groove of a shaft of a saw drum and interferes to turning of laying on a shaft and thus the arrangement of each pin of the next laying against each other. The arrangement of pins of the next laying against each other is obligatory since efforts of compression are perceived by pins and as required their shifts of a saw can be: are not clamped, clamped crookedly, and the laying basis can be damaged.

Existence of windows in laying promotes reduction of weight of laying and according to a saw drum, and the identical size and symmetric arrangement of windows it is necessary for ensuring the required residual imbalance of a saw drum.

\section{Results}

Table 1. Results of comparative experiments on the Alimkent cotton factory

\begin{tabular}{|c|c|c|c|}
\hline$\#$ & Indicators & Serial gin & Skilled gin \\
\hline 1 & $\begin{array}{c}\text { Contamination of cotton-raw, \% } \\
\text { a revolt } \\
\text { after the dryer drum } \\
\text { after cleaning on } \mathrm{YXK} \\
\text { a gin tray }\end{array}$ & $\begin{array}{l}2.28 \\
1.28 \\
0.36 \\
0.35\end{array}$ & $\begin{array}{l}2.42 \\
1.14 \\
0.37 \\
0.34\end{array}$ \\
\hline 2 & $\begin{array}{c}\text { Humidity of cotton-raw, \% } \\
\text { a revolt } \\
\text { after cleaning on } \mathrm{YXK} \\
\text { a gin tray }\end{array}$ & $\begin{array}{l}10.75 \\
8.09 \\
7.97\end{array}$ & $\begin{array}{l}10.51 \\
7.91 \\
7.80\end{array}$ \\
\hline 3 & $\begin{array}{c}\text { Damage of seeds, \% } \\
\text { a revolt } \\
\text { after the dryer drum } \\
\text { after cleaning on } \mathrm{YXK} \\
\text { a gin tray } \\
\text { after gin } \\
\text { after Linter }\end{array}$ & $\begin{array}{l}0.6 \\
1.3 \\
2.2 \\
2.7 \\
3.2 \\
9.59\end{array}$ & $\begin{array}{l}0.5 \\
1.2 \\
2.3 \\
1.6 \\
2.8 \\
8.02\end{array}$ \\
\hline 4 & $\begin{array}{c}\text { Mass fraction of defects and weed } \\
\text { impurity in fiber, } \% \\
\text { after gin } \\
\text { after the condenser }\end{array}$ & $\begin{array}{c}3.6 \\
3.24\end{array}$ & $\begin{array}{l}3.3 \\
3.0\end{array}$ \\
\hline 5 & $\begin{array}{c}\text { Pubescence of seeds, \% } \\
\text { after gin }\end{array}$ & 11.78 & 11.76 \\
\hline
\end{tabular}

Production tests of serial and skilled gins on Alimkent and Uzbekistan cotton factories of the Tashkent association Hlopkoprom for the purpose of check of results of the researches given in this chapter are carried out.

During production tests were studied a condition of grate lattices. It was established that between grates in the working area skilled gin had gaps approximately up to $4 \mathrm{~mm}$ and up 
to $5 \mathrm{~mm}$ at serial gin.

Results of production tests of serial gins and gins with the grates made on new technology and a saw cylinder of a new design after three months of operation in technological process are given in Table 1 .

Technological process of a ginning on skilled gin proceeds more steadily, as the proof of what serve indicators of quality of fiber.

So, for example, a mass fraction of defects and weed impurity in fiber made at serial gin $2.6 \%$ against $3.3 \%$ at skilled gin.

Polymeric between saw laying was established in saw gins in February, 2019 and was in operation until the end of a season of processing of a harvest. During operation more than twenty changes of a saw on a saw cylinder were made. The taken measurements showed that pins kept the initial sizes without changes after all changes of saws.

The carried-out tests showed reliability of work of skilled gin and completely confirmed results of the theoretical and pilot studies executed in vitro.

Taking into account all aforesaid, recommendations about use of a new way of production of grates and polymeric gin between saw laying at the enterprises of the cottonprocessing industry are made and approved as the first deputy chairman of the board of Uzkhlopkoprom association.

\section{Conclusions}

1) The size of a deflection of a saw cylinder has considerable impact not only on stability of technological process, but at the same time on intensity of wear of grates;

2) Mathematical models of flexural fluctuations of a shaft of a saw cylinder, a saw cylinder taking into account intensity of placement of the mass moments of inertia are made;

3) The model and a technique of the solution of the equation of flexural fluctuations of a saw cylinder with variable intensity of weight and flexural rigidity of sections is proved;

4) By the analytical analysis it is established that the elasticity of material of between saw laying has considerable impact on flexural rigidity of a saw cylinder (aluminum) and mass of a saw cylinder;

5) The new design of saw cylinders with use of the between saw laying made on a polymeric basis and equipped with steel pins which is protected by the RUz patent is developed;

6) The new design of a saw cylinder thanks to existence of the offered between saw laying has the smaller weight and big flexural rigidity;

7) Tests of a new design between saw laying on the Alimkent cotton factory of the Tashkent association "Pakhtasanoat" confirmed results of researches;

8) Recommendations about use of polymeric gin between saw laying at the enterprises of the cotton-processing industry are made and approved as the first deputy chairman of the board of Uzkhlopkoprom association;

9) Mass production of saw cylinders of a new design is developed.

\section{References}

1. A. Ismailov, R. Makhkamov, A. Ibragimov, M. Agzamov, J. Problems of textiles 3, 14 (2005)

2. R. Rosulov, Izvestiya Vysshikh Uchebnykh Zavedenii, Seriya Teknologiya Tekstil'noi Promyshlennosti, 2017(1), 119-122 (2017)

3. B. Sins, The cotton gin and mill press 3, 123-126 (1979) 
4. M. Agzamov, S. Yunusov, J Gafurov, IOP Conference Series: Materials Science and Engineering 254(8), 082017 (2017)

5. M. Agzamov, Izvestiya Vysshikh Uchebnykh Zavedenii, Seriya Teknologiya Tekstil'noi Promyshlennosti 2007(1), 26-29 (2007)

6. M. Agzamov, M. Agzamov, G. Madgidov, Izvestiya Vysshikh Uchebnykh Zavedenii, Seriya Teknologiya Tekstil'noi Promyshlennosti 2007(3), 34-37 (2007)

7. R. Makhkamov, M. Agzamov, Izvestiya Vysshikh Uchebnykh Zavedenii, Seriya Teknologiya Tekstil'noi Promyshlennosti 2006(2), 101-104 (2006)

8. S. Yunusov, European applied sciences 3, 79-85 (2015)

9. G. Holt, W. Laird, The Journal of Cotton Science 11, 79-90 (2007)

10. D. Muhammadiev, Kh. Akhmedov, B. Primov, F. Ibragimov, L. Zhamolova, T. Muhammadiev, Izvestiya Vysshikh Uchebnykh Zavedenii, Seriya Teknologiya Tekstil'noi Promyshlennosti 2020(2), 88-92 (2020) 